Supplement of Earth Surf. Dynam., 4, 125-145, 2016

http://www.earth-surf-dynam.net/4/125/2016/

doi:10.5194/esurf-4-125-2016-supplement

(C) Author(s) 2016. CC Attribution 3.0 License.

(c) (1)

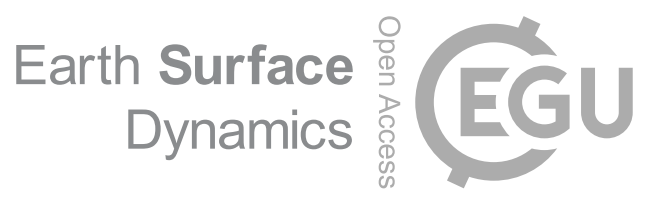

Supplement of

\title{
Efficacy of bedrock erosion by subglacial water flow
}

F. Beaud et al.

Correspondence to: F. Beaud (fbeaud@ sfu.ca)

The copyright of individual parts of the supplement might differ from the CC-BY 3.0 licence. 


\section{S1 Subglacial water flow model}

\section{S1.1 Channelized drainage}

The rate of channel closure is given by:

$v_{\mathrm{cc}}\left(S, N_{\mathrm{ch}}\right)=\tilde{A}_{\mathrm{ch}} S\left|N_{\mathrm{ch}}\right|^{n-1} N_{\mathrm{ch}}$,

5 where $\tilde{A}_{\text {ch }}$ is the ice flow-law coefficient adapted for a semi-circular channel, $S$ is the cross-sectional area of the channel, $n$ is the flow-law exponent, $N_{\mathrm{ch}}=\phi_{0}-\phi_{\mathrm{ch}}$ is the effective pressure in the channel $\phi_{\mathrm{ch}}$ is the hydraulic potential in the channel and $\phi_{0}=\rho_{\mathrm{w}} g z_{\mathrm{b}}+\rho_{\mathrm{i}} g h_{\mathrm{i}}$ is the hydraulic potential at the ice surface, with $g$ the gravitational acceleration, $z_{\mathrm{b}}$ the elevation of the bed, $\rho_{\mathrm{w}}$ and $\rho_{\mathrm{i}}$ the density of water and ice respectively, and $h_{\mathrm{i}}$ the ice thickness. The discharge $Q_{\mathrm{ch}}$ in a semi-circular channel reads

$Q_{\mathrm{ch}}=-k_{\mathrm{ch}} S^{\alpha_{\mathrm{c}}}\left|\nabla \phi_{\mathrm{ch}}\right|^{\beta_{\mathrm{c}}-2} \nabla \phi_{\mathrm{ch}}$,

where $k_{\mathrm{ch}}$ is the effective conductivity of a channel and $\alpha_{\mathrm{c}}$ and $\beta_{\mathrm{c}}$ are constants chosen for turbulent flow conditions (see Table S1). The dissipation of potential energy is expressed as

$\Xi=\left|Q_{\mathrm{ch}} \frac{\partial \phi_{\mathrm{ch}}}{\partial x}\right|$,

with $x$ the coordinate along the flowline. The energy required to maintain the water at the pressure melting point is given by

$\Pi=-c_{\mathrm{t}} c_{\mathrm{w}} \rho_{\mathrm{w}} Q_{\mathrm{ch}} \frac{\partial}{\partial x}\left(\phi_{\mathrm{ch}}-\phi_{\mathrm{b}}\right)$,

where $c_{\mathrm{t}}$ is the pressure melting coefficient for ice, $c_{\mathrm{w}}$ is the heat capacity of water and $\phi_{\mathrm{b}}$ the hydraulic potential at the bed elevation.

\section{S1.2 Network of linked cavities}

Cavity opening is a function of sliding speed $u_{\mathrm{b}}$ and bedrock obstacle size:

$v_{\mathrm{o}}\left(h_{\mathrm{ca}}\right)=\left\{\begin{array}{l}u_{\mathrm{b}}\left(h_{\mathrm{r}}-h_{\mathrm{ca}}\right) / l_{\mathrm{r}} \text { if } h_{\mathrm{ca}}<h_{\mathrm{r}} \\ 0 \text { otherwise, }\end{array}\right.$

where $h_{\mathrm{r}}$ and $l_{\mathrm{r}}$ are respectively the maximum height and length of characteristic bedrock obstacles and $h_{\mathrm{ca}}$ is the average height of the cavities. Cavity closure is caused by ice creep

$25 v_{\mathrm{c}}\left(h_{\mathrm{ca}}, N_{\mathrm{ca}}\right)=\tilde{A}_{\mathrm{ca}} h_{\mathrm{ca}}\left|N_{\mathrm{ca}}\right|^{n-1} N_{\mathrm{ca}}$,

where $\tilde{A}_{\text {ca }}$ is the ice flow-law coefficient adjusted for cavity geometry and $N_{\text {ca }}=\phi_{0}-\phi_{\text {ca }}$ is the effective pressure in the cavity network, with $\phi_{\text {ca }}$ the pressure in the network of cavities. The flux through the cavity system is expressed as

$\boldsymbol{q}_{\mathrm{ca}}=-K_{\mathrm{ca}} h_{\mathrm{ca}}^{\alpha}\left|\nabla \phi_{\mathrm{ca}}\right|^{\beta-2} \nabla \phi_{\mathrm{ca}}$, 
Table S1. Summary of hydrological model parameters.

\begin{tabular}{|c|c|c|}
\hline Parameter & Description & Value \\
\hline$M$ & Number of grid points & 101 \\
\hline $\mathrm{d} x$ & Cell size & $500 \mathrm{~m}$ \\
\hline $\mathrm{d} t$ & Time step & $600 \mathrm{~s}$ \\
\hline$W$ & System width & $1000 \mathrm{~m}$ \\
\hline$X_{\mathrm{L}}$ & Glacier length & $50 \mathrm{~km}$ \\
\hline$\rho_{\mathrm{w}}$ & Water density & $1000 \mathrm{~kg} \mathrm{~m}^{-3}$ \\
\hline$\rho_{\mathrm{i}}$ & Ice density & $910 \mathrm{~kg} \mathrm{~m}^{-3}$ \\
\hline$c_{\mathrm{w}}$ & Heat capacity of water & $4.22 \times 10^{3} \mathrm{~J} \mathrm{~kg}^{-1} \mathrm{~K}^{-1}$ \\
\hline$c_{\mathrm{t}}$ & Pressure melting coefficient & $7.5 \times 10^{-8} \mathrm{KPa}^{-1}$ \\
\hline$L$ & Latent heat of fusion & $3.34 \times 10^{5} \mathrm{~J} \mathrm{~kg}^{-1}$ \\
\hline$\tilde{A}_{\text {ch }}$ & Flow-law coefficient for channels ${ }^{\dagger}$ & $5 \times 10^{-25} \mathrm{~Pa}^{-\mathrm{n}} \mathrm{s}^{-1}$ \\
\hline$\tilde{A}_{\mathrm{ca}}$ & Flow-law coefficient for cavity network ${ }^{\dagger}$ & $5 \times 10^{-25} \mathrm{~Pa}^{-\mathrm{n}} \mathrm{s}^{-1}$ \\
\hline$n$ & Flow-law exponent & 3 \\
\hline$K_{\text {cav }}$ & Conductivity of linked cavity system & $1-25 \times 10^{-3} \mathrm{~m}^{7 / 4} \mathrm{~kg}^{-1 / 2}$ \\
\hline$k_{\mathrm{ch}}$ & Channel conductivity & 0.1225 (i.e. $\left\langle n^{\prime}\right\rangle=0.321$, Table $\left.\mathrm{S} 1\right\}$ \\
\hline$k_{\mathrm{ex}}$ & Exchange coefficient between cavities and channel & $5 \times 10^{-13} \mathrm{~m}^{3 / 2} \mathrm{~kg}^{-1 / 2}$ \\
\hline$\left\langle n^{\prime}\right\rangle$ & Manning roughness averaged & 0.0321 \\
\hline$n_{\mathrm{i}}^{\prime}$ & Manning roughness for ice & 0.01 \\
\hline$n_{\mathrm{b}}^{\prime}$ & Manning roughness for bed & 0.05 \\
\hline$e_{\mathrm{v}}$ & Englacial void ratio ${ }^{\dagger}$ & $1 \times 10^{-3}$ \\
\hline$h_{\mathrm{r}}$ & Height of bed obstacles & $0.2 \mathrm{~m}$ \\
\hline$l_{\mathrm{r}}$ & Length of bed obstacles ${ }^{\dagger}$ & $2 \mathrm{~m}$ \\
\hline$u_{\mathrm{b}}$ & Sliding speed & $5 \mathrm{ma}^{-1}$ \\
\hline$\alpha$ & Flux exponent for the cavity network ${ }^{\dagger}$ & $5 / 4$ \\
\hline$\alpha_{\mathrm{c}}$ & Flux exponent for the R-channel ${ }^{\dagger}$ & $5 / 4$ \\
\hline$\beta$ & Flux exponent for the cavity network ${ }^{\dagger}$ & $3 / 2$ \\
\hline$\beta_{\mathrm{c}}$ & Flux exponent for the R-channel ${ }^{\dagger}$ & $3 / 2$ \\
\hline$\gamma$ & Numerical compressibility parameter & $10^{-9} \mathrm{~Pa}^{-1}$ \\
\hline
\end{tabular}

${ }^{\dagger}$ Parameter values from Werder et al. (2013)

30 where $K_{\text {ca }}$ is the effective conductivity of the cavity system, and $\alpha$ and $\beta$ are again chosen to satisfy turbulent flow conditions (see Table S1). 


\section{S2 Shear stress partitioning}

To compute the viscous heat dissipation in semi-circular R-channels, the roughness of the bed and ice walls is averaged (Clarke, 2003). If $u$ is the average flow velocity in a channel or network of cavities, and $u=Q_{\mathrm{ch}} / S$ or $u=q_{\mathrm{ca}} / h_{\mathrm{ca}}$, respectively, the total shear stress on the ice walls and bed can be written

$\tau_{\text {tot }}=\frac{1}{8}\left\langle f_{\mathrm{R}}\right\rangle \rho_{\mathrm{w}} u^{2}$.

To account for the difference in roughness between the ice and bed, the averaged Darcy-Weisbach friction coefficient $\left\langle f_{\mathrm{R}}\right\rangle$ is given by (Clarke, 2003):

$\left\langle f_{\mathrm{R}}\right\rangle=\frac{f_{\mathrm{i}} P_{\mathrm{i}}+f_{\mathrm{b}} P_{\mathrm{b}}}{P_{\mathrm{w}}}$,

where $f_{\mathrm{i}}$ and $f_{\mathrm{b}}$ are, respectively, the friction coefficients of the ice and bed, and $P_{\mathrm{i}}, P_{\mathrm{b}}$ and $P_{\mathrm{w}}$ are the ice, bed and total wetted perimeters, respectively. Given that $f_{a}=\left(8 g n_{a}^{\prime 2}\right) / R_{\mathrm{H}}^{1 / 3}$, with $a$ representing either the ice $\mathrm{i}$ or the bed $\mathrm{b}$ and $R_{\mathrm{H}}$ being the hydraulic radius. After substitution the averaged Manning roughness is

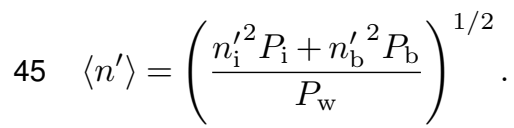

Here, $n_{\mathrm{i}}^{\prime}$ and $n_{\mathrm{b}}^{\prime}$ are the Manning roughness of the ice and the bed respectively. The partitioning of the shear stress is obtained through the sum of the shear stresses weighted by the normalized wetted perimeters of the respective materials:

$\tau_{\text {tot }}=\frac{\tau_{\mathrm{i}} P_{\mathrm{i}}}{P_{\mathrm{w}}}+\frac{\tau_{\mathrm{b}} P_{\mathrm{b}}}{P_{\mathrm{w}}}$.

50 The shear stress on either the ice $\left(\tau_{\mathrm{i}}\right)$ or bed $\left(\tau_{\mathrm{b}}\right)$ is computed using Eq. S8 replacing $\left\langle f_{\mathrm{R}}\right\rangle$ by $f_{\mathrm{i}}$ or $f_{\mathrm{b}}$. For the shear stress on the bed this leads to

$\tau_{\mathrm{b}}=\frac{1}{8} f_{\mathrm{b}} \rho_{\mathrm{w}} u^{2}$.

We use a formulation of the discharge in a channel that is not a direct function of the Manning roughness or the Darcy-Weisbach friction coefficient but rather an effective channel conductivity $k_{\mathrm{ch}}($ Table S1) which is given by

$k_{\mathrm{ch}}=\left(\rho_{\mathrm{w}} g n^{\prime 2}\left(\frac{2}{\pi}\right)^{2 / 3}(\pi+2)^{4 / 3}\right)^{-1 / 2}$

as a function of the Manning roughness $n^{\prime}$, or

$k_{\mathrm{ch}}=\left(\frac{8}{\rho_{\mathrm{w}} f_{\mathrm{R}}\left(\frac{2}{\pi}\right)^{1 / 2}(\pi+2)}\right)^{1 / 2}$

as a function of Darcy-Weisbach roughness $f_{R}$. 


\section{S3.1 Saltation erosion model (SEM)}

\section{S3.1.1 Hop height $H_{\mathrm{s}}$ and length $L_{\mathrm{s}}$}

Sklar and Dietrich (2004) determined that the best empirical fit for the hop height could be written as

$65 H_{\mathrm{s}}=1.44 D\left(\frac{\tau^{*}}{\tau_{\mathrm{c}}^{*}}-1\right)^{0.5}$,

and the hop length as

$L_{\mathrm{s}}=8.0 D \frac{\left(\tau^{*} / \tau_{\mathrm{c}}^{*}-1\right)^{0.88}}{\left(1-\left(u^{*} / w_{\mathrm{f}}\right)^{2}\right)^{1 / 2}}$ for $u^{*} / w_{\mathrm{f}}<1$,

where $D$ is the particle diameter, $w_{\mathrm{f}}$ is the terminal settling velocity of a particle, $\tau^{*}$ is the Shields stress, $\tau_{\mathrm{c}}^{*}$ its critical value for sediment motion and $u^{*}$ the shear velocity. When the shear velocity exceeds the settling velocity $\left(u^{*} / w_{\mathrm{f}} \geq 1\right)$ the particle is in suspension and the hop length becomes infinite. The settling velocity of a particle is computed following Dietrich (1982), who defines a dimensionless fall velocity $W_{*}$ and particle diameter $D_{*}$ as:

$W_{*}=\frac{\rho_{\mathrm{w}} w_{\mathrm{f}}^{3}}{\left(\rho_{\mathrm{s}}-\rho_{\mathrm{w}}\right) g \nu}$

$75 D_{*}=\frac{\left(\rho_{\mathrm{s}}-\rho_{\mathrm{w}}\right) g D^{3}}{\rho_{\mathrm{w}} \nu}$,

where $\nu$ is the kinematic viscosity of water and $\rho_{\mathrm{s}}$ is the density of the particle. The dimensionless fall velocity is found empirically to be

$W_{*}=R_{3} \times 10^{R_{1}+R_{2}}$,

where

$$
\begin{array}{r}
R_{1}=-3.76715+1.92944 \log \left(D_{*}\right)-0.09815 \log \left(D_{*}\right)^{2.0} \\
-0.00575 \log \left(D_{*}\right)^{3.0}+0.00056 \log \left(D_{*}\right)^{4.0}
\end{array}
$$

$$
\begin{array}{r}
R_{2}=\log \left(1-\frac{1-\mathrm{CSF}}{0.85}\right)-(1-\mathrm{CSF})^{2.3} \tanh \left(\log \left(D_{*}\right)-4.6\right) \\
+0.3(0.5-\mathrm{CSF})(1-\mathrm{CSF})^{2.0}\left(\log \left(D_{*}\right)-4.6\right)
\end{array}
$$

and

$$
R_{3}=\left[0.65-\left(\frac{\mathrm{CSF}}{2.83} \tanh \left(\log \left(D_{*}\right)-4.6\right)\right)\right]^{1+\left(3.5-P_{\mathrm{nb}}\right) / 2.5}
$$


Table S2. Summary of parameter values for the SEM (Sect.2.2.1) and TLEM (Sect.2.2.2.

\begin{tabular}{lll}
\hline Parameter & Description & Value \\
\hline$\nu$ & Kinematic viscosity of water & $10^{-6} \mathrm{~m}^{2} \mathrm{~s}^{-1}$ \\
$P_{\mathrm{nb}}$ & Powers number & 3.5 \\
$\mathrm{CSF}$ & Corey shape factor & 0.8 \\
\hline
\end{tabular}

85 Here $P_{\mathrm{nb}}$ is the Powers number and CSF the Corey shape factor. Together these numbers define the shape of the particle. The dimensional fall velocity can then be computed by inverting Eq. $S 17$ :

$w_{\mathrm{f}}=\left(\frac{W_{*}\left(\rho_{\mathrm{s}}-\rho_{\mathrm{w}}\right) g \nu}{\rho_{\mathrm{w}}}\right)^{1 / 3}$.

\section{S3.1.2 Impact velocity $w_{\text {si }}$}

From the fall velocity, Sklar and Dietrich (2004) compute the mean particle descent velocity $w_{\text {sd }}$ as

$90 w_{\mathrm{sd}}=\frac{3 H_{\mathrm{s}} U_{\mathrm{s}}}{2 L_{\mathrm{s}}}=0.4(r g D)^{1 / 2}\left(\frac{\tau^{*}}{\tau_{\mathrm{c}}^{*}}-1\right)^{0.18}\left(1-\left(\frac{u^{*}}{w_{\mathrm{f}}}\right)^{2}\right)^{1 / 2}$,

where $r=\rho_{\mathrm{s}} / \rho_{\mathrm{w}}-1$ is the buoyant density of sediment and the along-path velocity of particles travelling as bedload is given by

$U_{\mathrm{s}}=1.56(r g D)^{1 / 2}\left(\frac{\tau^{*}}{\tau_{\mathrm{c}}^{*}}-1\right)^{0.56}$.

They further estimate that the impact velocity is twice the mean descent velocity

$95 w_{\mathrm{si}} \approx 2 w_{\mathrm{sd}}$.

\section{S3.2 Total load erosion model (TLEM)}

For the suspended load, the sediment concentration can be written

$c=c_{\mathrm{b}}\left(\frac{\left(1-\zeta_{\mathrm{z}}\right) / \zeta_{\mathrm{z}}}{\left(1-\zeta_{\mathrm{b}}\right) / \zeta_{\mathrm{b}}}\right)^{P_{\mathrm{R}}}$

where we define $\zeta_{\mathrm{z}}=z / H$ and $\zeta_{\mathrm{b}}=H_{\mathrm{s}} / H, H$ is the height of the flow and $P_{\mathrm{R}}=w_{\mathrm{st}} /\left(\kappa u^{*}\right)$ is the Rouse parameter while $\kappa$ is von Karman's constant. The near-bed sediment concentration $c_{\mathrm{b}}$ is defined as:

$c_{\mathrm{b}}=\frac{q_{\mathrm{s}}}{u H \chi+U_{\mathrm{s}} H_{\mathrm{s}}}$,

where $q_{\mathrm{s}}$ is the sediment supply per unit width. The integral relating the flux of sediment to $c_{\mathrm{b}}, H$ and $u$ is given by:

$105 \chi=\frac{1}{u H} \int_{H_{\mathrm{s}}}^{H}\left(\frac{\left(1-\zeta_{\mathrm{z}}\right) / \zeta_{\mathrm{z}}}{\left(1-\zeta_{\mathrm{b}}\right) / \zeta_{\mathrm{b}}}\right)^{P_{\mathrm{R}}} \frac{u^{*}}{\kappa} \ln \left(\frac{z}{z_{0}}\right) \mathrm{d} x$ 
and the bed load transport capacity is expressed as

$q_{\mathrm{b}}=c_{\mathrm{b}} U_{\mathrm{s}} H_{\mathrm{s}}=\frac{q_{\mathrm{s}} U_{\mathrm{s}} H_{\mathrm{s}}}{u H \chi+U_{\mathrm{s}} H_{\mathrm{s}}}$.

Because the effect of turbulence on sediment concentration has been introduced, the equation for the impact velocity (Eq. (S26) proposed by Sklar and Dietrich (2004) is no longer valid. Instead, the effective impact velocity is written as a function of velocity fluctuations $w^{\prime}$ close to the bed:

$w_{\mathrm{i}, \mathrm{eff}}=\left(\int_{-w_{\mathrm{s}}}^{6 \sigma_{\mathrm{w}}}\left(w^{\prime}+w_{\mathrm{s}}\right)^{3} P \mathrm{~d} w^{\prime}\right)^{1 / 3}$,

where $\sigma_{\mathrm{w}}=\sqrt{\overline{{w^{\prime}}^{2}}}$ is the standard deviation of velocity fluctuations (the over line denotes averaging; as an approximation for open flows $\sigma_{\mathrm{w}}=u^{*}$ ) and $P$ is a probability density function of the velocity fluctuations such that

$115 P\left(w^{\prime}\right)=\frac{1}{\sqrt{2 \pi} \sigma_{\mathrm{w}}} \exp \left(-\frac{w^{\prime 2}}{2 \sigma_{\mathrm{w}}^{2}}\right)$.

Note that $w^{\prime}$ is taken as a variable such that $w^{\prime} \in\left[-w_{\mathrm{s}}, 6 \sigma_{\mathrm{w}}\right]$. The velocity normal to the bed of a falling particle $w_{\mathrm{s}}$ is given by

$w_{\mathrm{s}}=w_{\mathrm{st}} \cos (\theta) \sqrt{1-\exp \left(-\frac{3 C_{\mathrm{d}} \rho_{\mathrm{w}} H_{\mathrm{f}}}{2 \rho_{\mathrm{s}} D \cos (\theta)}\right)}$,

where $w_{\mathrm{st}}$ is the terminal settling velocity, $\theta$ is the slope of the bed, $C_{\mathrm{d}}$ is the drag coefficient and

$H_{\mathrm{f}}$ is the particle fall distance. The terminal settling velocity is computed as

$w_{\mathrm{st}}=\left(\frac{4}{3} \frac{r g D}{C_{\mathrm{d}}}\right)^{1 / 2}$

and the drag coefficient as

$C_{\mathrm{d}}=\frac{4}{3} \frac{\left(\rho_{\mathrm{s}}-\rho_{\mathrm{w}}\right) g D}{\rho_{\mathrm{w}} w_{\mathrm{f}}^{2}}$.

Finally, the fall distance is a function of the sediment concentration throughout the water column $(c)$ :

$H_{\mathrm{f}}=\frac{1}{c_{\mathrm{b}}} \int_{H}^{H_{\mathrm{s}}} z \frac{\mathrm{d} c}{\mathrm{~d} z} \mathrm{~d} z$

where $z$ is the height above the bed. 

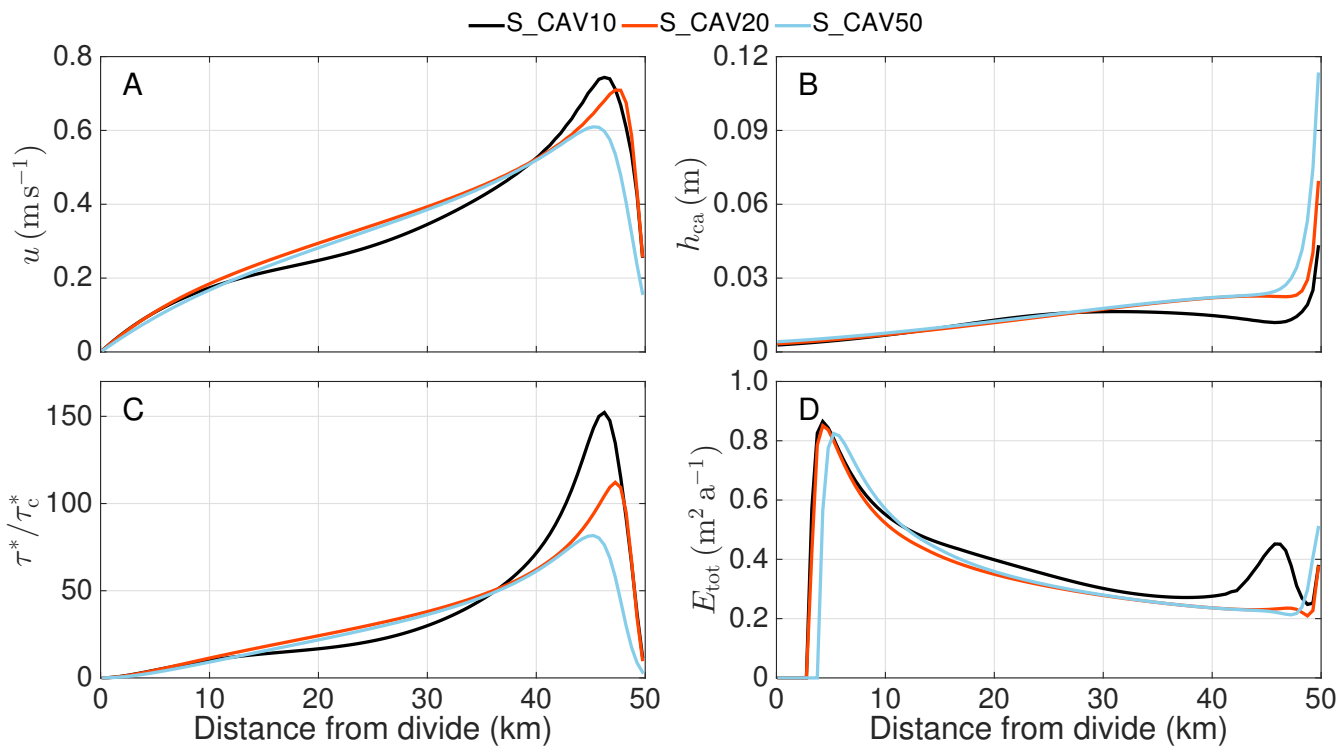

Figure S1. Comparison of the hydraulic conditions, transport stage and erosion in a network of cavities for different sliding speeds $\left(u_{\mathrm{b}}=10-50 \mathrm{~m} / \mathrm{a}, \mathrm{S} \_\right.$CAV10 -50 , Table S3, Sect.S4.1). (A) Water velocity $u$; (B) Height of cavities $h_{\mathrm{ca}}$; (C) Transport stage $\tau^{*} / \tau_{\mathrm{c}}^{*}$; (D) Total erosion $\left(E_{\mathrm{tot}}=\dot{e}_{\mathrm{tot}} W\right)$ computed with the TLEM. Transport stage and erosion are computed for sand particles with a diameter $D=1 \mathrm{~mm}$.

\section{S4 Supplementary steady state simulations}

\section{S4.1 Linked cavities}

Here we ask whether water flow through a network of linked cavities is capable of bedrock erosion, in tests using a fixed ice geometry and surface melt profile, but variable sliding speeds. The opening term in the cavity evolution equation (Eq. $(\mathrm{S} 5$ ) ) is a function of effective pressure, sliding speed and geometry of bed obstacles. Since the latter is poorly defined and we prescribe ice geometry, we choose to vary only the sliding speed in these tests (Table 53 ). We assume a sediment size corresponding to coarse sand $(D=1 \mathrm{~mm})$ in anticipation of much lower transport capacities than in a channel. We also divide the reference reach-averaged sediment supply $\left(q_{\mathrm{s}, \text { ref }}\right.$; Table 2$)$ by the width of the glacier $(W)$ such that $q_{\mathrm{s}, \mathrm{cav}}=q_{\mathrm{s}, \mathrm{ref}} / W$.

The flow velocity through the cavity network (Fig. $[\mathrm{S1}$ A) shows similar features to the simulation S_MOULIN (see Fig.2B). Close to the terminus the ice thins rapidly (Fig.11), reducing creep closure and leading to larger cavities (Fig. $\mathrm{S1B}$; Eq. $[\mathrm{S5}$ ). The increase in cavity size over the last $2 \mathrm{~km}$ of the bed is accentuated if sliding speeds are relatively large (largest cavities for S_CAV50 simulation, Table $\mathbf{S 3}$, and the increase in cavity size drives the drop in velocity (Fig. $\mathbf{S 1} \mathrm{B} ; u=q_{\mathrm{w}} / h_{\text {cav }}$ ). In turn the larger the sliding speed, the larger the transport stage (Fig. S1. C). 
Table S3. Summary of steady state simulations. For simulations in which meltwater input is a function of ice-surface elevation $z_{\mathrm{s}}$, we compute $f\left(z_{\mathrm{s}}(x)\right)=\dot{b}_{\mathrm{ss} \max } \times\left(1-\left(z_{\mathrm{s}}(x)-z_{\mathrm{s}, \min }\right) / z_{\mathrm{s}, \max }\right)$, where $\dot{b}_{\mathrm{ss} \max }=$ $8.5 \times 10^{-7} \mathrm{~ms}^{-1}$ is the maximum melt water input rate to the channelized drainage system, and $z_{\mathrm{s}, \min }$ and $z_{\mathrm{s}, \max }$ are respectively the minimum and maximum ice-surface elevations. Note that $\dot{b}_{\mathrm{ss} \max }=8.5 \times 10^{-7} \mathrm{~ms}^{-1}$ corresponds to $7.6 \mathrm{~cm}$ of ice melt per day assuming $\rho_{\mathrm{i}}=910 \mathrm{~kg} \mathrm{~m}^{-3}$. The reference sediment supply used for the steady state simulations is: $q_{\mathrm{s}, \mathrm{ref}}=3.6 \times 10^{-3} \mathrm{~m}^{2} \mathrm{~s}^{-1}$.

\begin{tabular}{|c|c|c|c|c|}
\hline Simulation & Purpose & Forcing & Difference from reference run & Section \\
\hline S_MOULIN & R-channel only & $Q_{\mathrm{ch}}(x=0, t)=4.25 \mathrm{~m}^{3} \mathrm{~s}^{-1}$ & Localized input upstream boundary & 4.1 .1 \\
\hline S_CAV10-50 & Cavities only & $\dot{b}_{\mathrm{cav}}(x, t)=f\left(z_{\mathrm{s}}(x)\right)$ & $\begin{array}{l}\text { Network of cavities only with } \\
u_{\mathrm{b}}=10-50, D=1 \mathrm{~mm}\end{array}$ & S4.1 \\
\hline S_REF & Reference & $\dot{b}_{\mathrm{ch}, \mathrm{ref}}(x, t)=f\left(z_{\mathrm{s}}(x)\right)$ & & 4.1 .2 \\
\hline S_CST & Water input & $\dot{b}_{\mathrm{ch}}(x, t)=4.25 \times 10^{-7} \mathrm{~ms}^{-1}$ & $\dot{b}_{\text {ch }}$ constant in space & S4.2 \\
\hline S_CSTx2 & Water input & $\dot{b}_{\mathrm{ch}}(x, t)=8.5 \times 10^{-7} \mathrm{~ms}^{-1}$ & $2 \times \dot{b}_{\text {ch }}$ from S_CST & S4.2 \\
\hline S_SURFx2 & Water input & $\dot{b}_{\mathrm{ch}}(x, t)=\dot{b}_{\mathrm{ch}, \mathrm{ref}} \times 2$ & $2 \times \dot{b}_{\mathrm{ch}}$ from REF & $\mathrm{S} 4.2$ \\
\hline S_SSZ & Sediment size & $\dot{b}_{\mathrm{ch}}(x, t)=\dot{b}_{\mathrm{ch}, \mathrm{ref}}$ & $D=1-550 \mathrm{~mm}$ & S4.3 \\
\hline S_MR23 & Manning roughness & $\dot{b}_{\mathrm{ch}}(x, t)=\dot{b}_{\mathrm{ch}, \mathrm{ref}}$ & $n_{\mathrm{i}}^{\prime}=0.010, n_{\mathrm{b}}^{\prime}=0.035,<n^{\prime}>=0.023$ & S4.4 \\
\hline S_MR35 & Manning roughness & $\dot{b}_{\mathrm{ch}}(x, t)=\dot{b}_{\mathrm{ch}, \mathrm{ref}}$ & $n_{\mathrm{i}}^{\prime}=0.020, n_{\mathrm{b}}^{\prime}=0.050,<n^{\prime}>=0.035$ & S4.4 \\
\hline S_MR38 & Manning roughness & $\dot{b}_{\mathrm{ch}}(x, t)=\dot{b}_{\mathrm{ch}, \mathrm{ref}}$ & $n_{\mathrm{i}}^{\prime}=0.010, n_{\mathrm{b}}^{\prime}=0.060,<n^{\prime}>=0.038$ & S4.4 \\
\hline S_MR46 & Manning roughness & $\dot{b}_{\mathrm{ch}}(x, t)=\dot{b}_{\mathrm{ch}, \mathrm{ref}}$ & $n_{\mathrm{i}}^{\prime}=0.020, n_{\mathrm{b}}^{\prime}=0.070,<n^{\prime}>=0.046$ & S4.4 \\
\hline
\end{tabular}

Particle motion is initiated over most of the bed $\left(\tau^{*} / \tau_{\mathrm{c}}^{*}>1\right.$; Fig. .S1C) and transport stages are particularly high $\left(\tau^{*} / \tau_{\mathrm{c}}^{*}>2\right.$; Fig. $\left.\mathrm{S} 1 \mathrm{C}\right)$, hence erosion rates are limited by the decrease in relative sediment supply $\left(q_{\mathrm{s}} / q_{\mathrm{tc}}\right)$. As a result, erosion peaks between $\mathrm{km} 4$ and 5 (Fig. S1P) and decreases thereafter until near the terminus. Close to the terminus, transport stage drops while remaining above 5, thus erosion increases again. In simulation S_CAV10, the local peak in erosion at km 48 (Fig.S1P) occurs due to the peak in transport stage (Fig. $[\mathrm{S1}$ C) that allows the high impact velocity to offset the low relative sediment supply rate.

\section{S4.2 Water input}

Subglacial discharge is largely controlled by the amount and distribution of melt water reaching the bed. Alley et al. (1997) suggest that the transport capacity of a subglacial channel is an exponential function of discharge $\left(Q_{\mathrm{tc}} \propto Q_{\mathrm{ch}}^{9 / 2}\right)$. We compare the effect of (1) feeding the system through a single moulin at the upstream domain boundary (S_MOULIN, Table S3, (2) a constant water input throughout the profile (S_CST and S_CSTx2, Table S3 and (3) water input varying inversely with ice-surface elevation (S_REF and S_SURFx2, Table S3). In tests S_CSTx2 and S_SURFx2 the water input rate is doubled compared to S_CST and S_REF, respectively. 


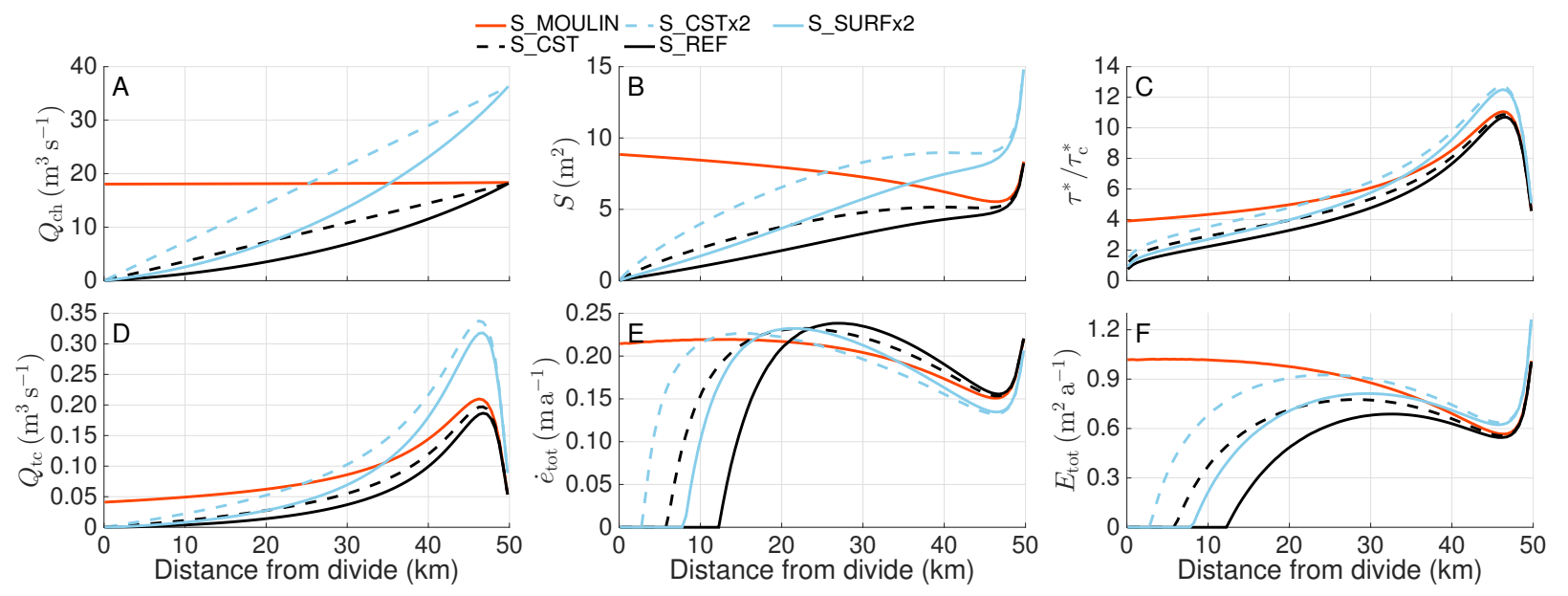

Figure S2. Comparison of steady state results for varying surface melt scenarios, reference ice geometry (Fig.1) and drainage through one R-channel (Table 3 reference and water input; Sect.4.1.2). The legend applies to all panels. (A) Discharge in the R-channel, $Q_{\mathrm{ch}}$; (B) Cross-sectional area of the channel, $S$; (C) Transport stage, $\tau^{*} / \tau_{\mathrm{c}}^{*}$; (D) Total transport capacity in the channel, $Q_{\mathrm{tc}}=q_{\mathrm{tc}} \times W_{\mathrm{ch}}$; (E) Erosion rate per unit width calculated with the TLEM, $\dot{e}_{\text {tot }}$; Total erosion computed with the TLEM, $E_{\text {tot }}=\dot{e}_{\text {tot }} \times W_{\text {ch }}$.

Water velocity in a channel is dependent on channel discharge and cross-sectional area. The latter is controlled by the ratio of melt opening to creep closure and is thus sensitive to ice thickness (Eqs (1)-(S2). As expected, the larger the water input, and hence the discharge (Fig. $\mathbf{S 2}$ A), the larger the cross-sectional area of the channel (Fig. $\mathbf{S} 2 \mathrm{~B})$. Peaks in transport stage $\left(\tau^{*} / \tau_{\mathrm{c}}^{*} ; \mathrm{Fig} . \mathrm{S} 2 \mathrm{C}\right)$ coincide with the kink in the channel size profile (between $\mathrm{km} 46$ and 47) similarly to what is seen in Fig. 2 .

Since the channel cross-sectional area increases by about an order of magnitude along the profile (except for S_MOULIN since $Q_{\mathrm{ch}}=\mathrm{cst}$ ), the amplitude of total transport capacity ( $Q_{\mathrm{tc}}$, Fig. $\left.\mathbf{S} 2 \mathrm{p}\right)$ is enhanced by about an order of magnitude compared to that of the reach-averaged transport capacity $\left(q_{\mathrm{tc}}\right.$, not shown). Despite the large increase in channel size close to the terminus, the decrease in transport stage $\left(\tau^{*} / \tau_{\mathrm{c}}^{*}\right.$; Fig. $\mathrm{S2}$ C) is large enough that the total transport capacity still declines by a factor of two to three $\left(Q_{\mathrm{tc}}\right.$, Fig. $\left.\mathrm{S2} \mathrm{D}\right)$.

All simulations in Fig. S2 but S_MOULIN show a sharp increase in erosion rate per unit width $\left(\dot{e}_{\text {tot }}\right.$, Fig. S2 $\left.\mathrm{E}\right)$ and total erosion $\left(E_{\text {tot }}\right.$, Fig. $\left.52 \mathrm{~F}\right)$ commensurate with the increase of total transport capacity $Q_{\mathrm{tc}}$ from zero near the divide (km 3 for S_CSTx 2 and $\mathrm{km} 12$ for S_REF). A local maximum in erosion rates ( $\dot{e}_{\text {tot }}$, Fig. $\mathrm{S} 2 \mathrm{E}$ ) occurs when the fraction exposed $F_{\mathrm{e}}$ reaches 0.7 (not shown); for higher transport stages, due to the constant sediment supply, the lack of tools $\left(c_{\mathrm{b}}<9 \times 10^{-3}\right.$ and $q_{\mathrm{s}} / q_{\mathrm{tc}}<0.3$, not shown; see Fig.2) drives erosion rates down until km 47 (Fig. S2E). Closer to the terminus, the transport stage drops $\left(\tau^{*} / \tau_{c}^{*}\right.$, Fig. S2 $\left.\mathrm{C}\right)$, the number of tools increases and so 


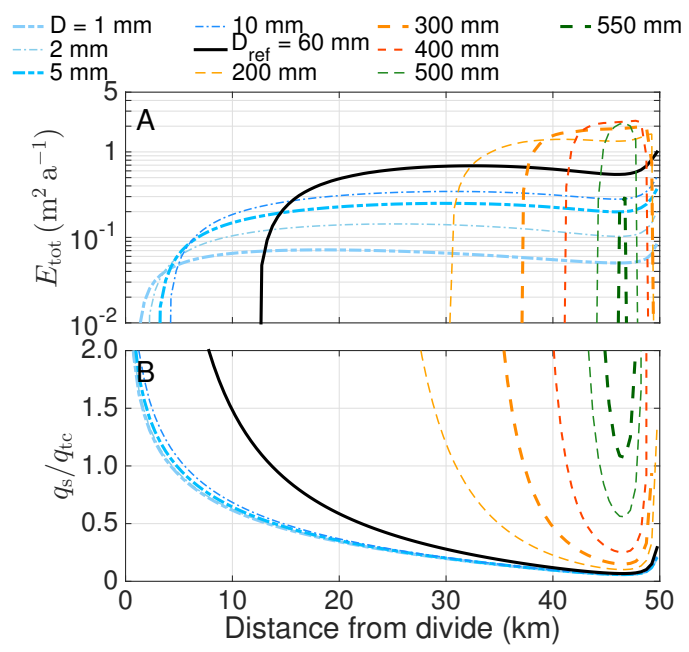

Figure S3. Influence of sediment size $D$ (S_SSZ, Table S3) on total erosion with the TLEM for the same hydrology as in the reference simulation (S_REF, TableS3). (A) Total erosion rate computed with the TLEM $\left(E_{\mathrm{tot}}\right)$; (B) Relative sediment supply $\left(q_{\mathrm{s}} / q_{\mathrm{tc}}\right)$.

does erosion. Because of the feedback by which the number of tools in the vicinity of the bed and the erosion rates decrease with increasing transport stage, the erosion per unit width is highest for S_REF (Table 3) and lowest for S_CSTx2 and S_MOULIN (Table S3).

Profiles of total erosion ( $\left.E_{\mathrm{tot}}, \mathrm{Fig} . \mathrm{S2} \mathrm{F}\right)$ are very similar to profiles of erosion rate per unit width (Fig. S2E). For a given ice geometry, increased steady state discharge leads to larger channels thus larger peaks in total erosion. The doubling in surface melt between S_REF and S_SURFx2 (Table $\mathrm{S3}$ leads to an increase of only $\sim 33 \%$ in total erosion integrated over the glacier length.

\section{S4.3 Sediment size}

Increasing the particle size is equivalent to a reduction in transport capacity (Eqs. (13) and (12)) and will affect rates and patterns of erosion (Fig. 15 in Sklar and Dietrich (2004); Fig. 7 in Lamb et al. (2008)). We show in Fig. S3 that varying the particle diameter from sand- to boulder-sized leads to similar patterns as variations in sediment supply rate (Fig. S3. When explained in terms of the relative sediment supply $\left(q_{\mathrm{s}} / q_{\mathrm{tc}}\right)$, the feedbacks are those described in Fig. 4 . In the case of particle size it is the decrease in transport capacity, rather that the increase in sediment supply, that yields larger relative sediment supply. We do not display the results of the SEM since the patterns are similar, despite the fact that little to no erosion occurs for the smallest particles $(D=1-2 \mathrm{~mm})$ which travel mostly in suspension. 


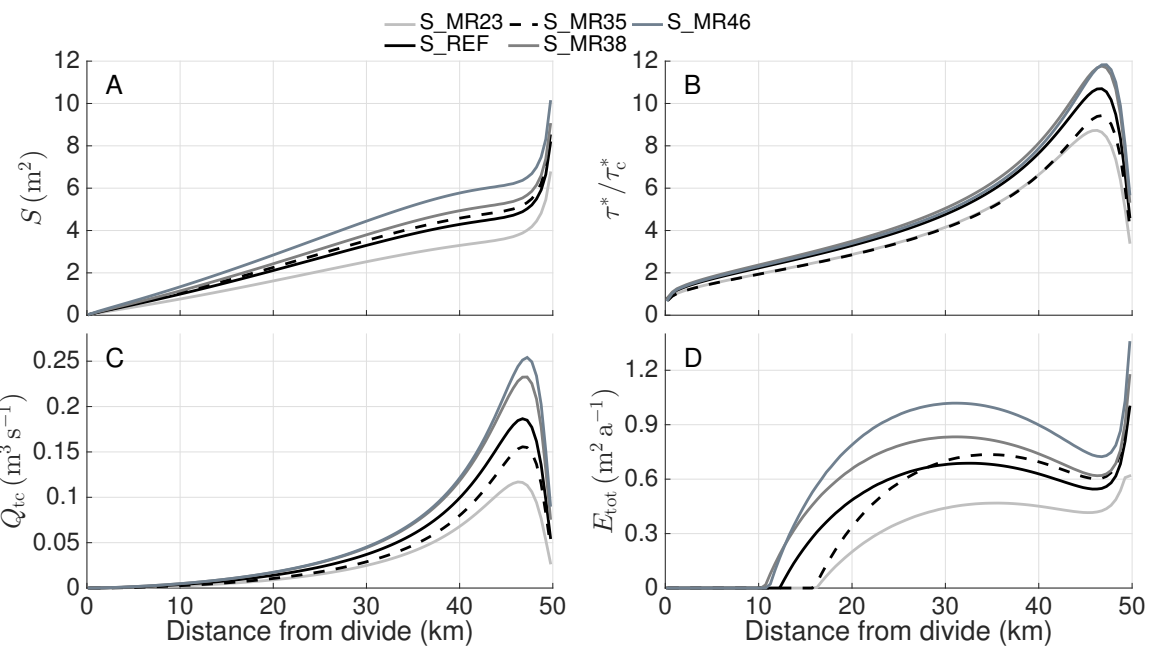

Figure S4. Influence of bed and channel wall roughness on erosion and transport capacity. (A) Channel crosssectional area $S$; (B) Transport stage $\tau^{*} / \tau_{\mathrm{c}}^{*}$; (C) Total transport capacity $Q_{\mathrm{tc}}$; (D) Total erosion computed with the TLEM $E_{\text {tot. }}$.

\section{S4.4 R-channel roughness and steady state conditions}

We discuss here the effect of the roughness of the ice walls and of the bed material (Clarke, 2003) since these parameters are poorly constrained. A smaller roughness would lead to less viscous heat dissipation and less melt of the channel, but also to a lower shear stress on the bed. We test different roughness combinations (see Table S3, Eqs. (S8)-66; Fig. S4] while the discharge is kept constant (see Fig.S2A, solid black), to differentiate the effect of bed and ice wall roughness.

As expected, the larger the average roughness, the larger the channel (Fig.S4A). The transport stage (Fig. S4 B), on the other hand, is dependent on bed roughness (Eq. (6)). When we only increase the ice wall roughness (S_MR35) the channel grows larger, but the transport stage remains lower than in the reference simulation (S_REF) because the average water flow velocity is lower. The total transport capacity (Fig. $\mathrm{S} 4 \mathrm{C}$ ) follows the same general hierarchy between simulations as the transport stage. In terms of the total erosion rates (Fig.S4D), simulations with larger averaged Manning roughness (e.g. S_MR23 vs. S_MR46) produce more erosion. 


\section{References}

Alley, R. B., Cuffey, K. M., Evenson, E. B., Strasser, J. C., Lawson, D. E., and Larson, G. J.: How glaciers entrain and transport basal sediment: Physical constraints, Quaternary Sci. Rev., 16, 1017-1038, 1997.

Clarke, G. K. C.: Hydraulics of subglacial outburst floods: new insights from the Spring-Hutter formulation, J. Glaciol., 49, 299-313, 2003.

Dietrich, W. E.: Settling velocity of natural particles, Water Resour. Res., 18, 1615-1626, 1982.

Lamb, M. P., Dietrich, W. E., and Sklar, L. S.: A model for fluvial bedrock incision by impacting suspended 215 and bed load sediment, J. Geophys. Res., 113, F03 025, 2008.

Sklar, L. S. and Dietrich, W. E.: A mechanistic model for river incision into bedrock by saltating bed load, Water Resour. Res., 40, W06 301, 2004.

Werder, M. A., Hewitt, I. J., Schoof, C., and Flowers, G. E.: Modeling channelized and distributed drainage in two dimensions, J. Geophys. Res.-Earth, 118, 2140-2158, 2013. 